\title{
COMMENT
}

\section{Tethering experiments and hypothesis testing in ecology}

\author{
Richard B. Aronson, Kenneth L. Heck Jr
}

\author{
Marine Environmental Sciences Consortium, Dauphin Island Sea Lab, Dauphin Island, Alabama 36528, USA, and \\ Department of Marine Sciences, University of South Alabama, Mobile, Alabama 36688, USA
}

In attempting to understand biological processes such as competition and predation, terrestrial ecologists have the leisure to make extensive direct observations of interacting organisms. Benthic ecologists, in contrast, are usually constrained by time and tide. Tidal cycles in the intertidal and scuba air supply in the subtidal often limit opportunities to observe natural competitive and predator-prey interactions. Instead, benthic ecologists rely on a variety of experimental techniques to illuminate pattern and process. One method used to compare predation in different habitats, and predation on different prey within the same habitat, is to restrain the prey for some period and then document their predation-related mortality. Procedures of this type are known as tethering experiments. Tethering experiments have the advantage of removing the observer from the site of the experiment, thereby reducing the probability of unnatural behaviors of predators in reaction to humans.

A recent paper by Peterson \& Black (1994) criticizes the use of tethering techniques in predation studies. According to their survey of 22 published papers, only a slim majority of authors consider that the mortality rates of tethered prey do not measure natural mortality rates. Peterson \& Black (1994) refer to these biases introduced by tethering as 'simple artifacts'. Even fewer authors, according to their literature review, consider that the reactions of predators to tethered prey can differ among treatments (i.e. across habitats or across prey types within habitats). If the behavior of consumers varies across treatments, then the tethering experiments are not properly controlled, confounding the interpretation of results. Peterson \& Black (1994) term such potential problems 'second-order artifacts'. They state that few of the 22 papers attempt to evaluate the possibility of an among-treatment bias.

Although they raise several important issues, we believe that Peterson \& Black (1994) strike out at tethering studies without sufficiently considering what those studies represent. We argue that Peterson \& Black (1994) have overgeneralized in concluding that benthic ecologists infrequently consider artifacts when drawing conclusions based on tethering experiments.
We present some examples from our own work, which includes 6 of the 22 papers reviewed.

Criticisms of tethering. One troublesome aspect of Peterson \& Black's (1994) paper is that the literature review is inaccurate. In their Table 1 they present a sample of the many studies that have employed tethering experiments, accompanied by their (Peterson \& Black's) opinions about whether the papers addressed tethering artifacts. In one study (Aronson 1988), 5 species of ophiuroids were tethered and presented in a prey-choice experiment to predatory reef fishes in the Caribbean. According to their table, Aronson (1988) does not discuss simple tethering artifacts, nor does he mention second-order artifacts, meaning in this case the possibility of interaction between the tethering method and the different ophiuroid species. Yet Aronson (1988) explicitly states that the tethering method used 'does not release predator-attracting body fluids'. $\mathrm{He}$ also refers the reader to 2 other papers, Witman (1985) and Aronson (1987), which discuss tethering artifacts in more detail. Since body fluids emanating from different ophiuroid species could conceivably affect predators in different ways, the paper also rules out that type of interaction between the tethering method and the treatments.

Heck \& Wilson (1987) appears in Peterson \& Black's (1994) Table 1 as an example of a paper that discusses simple tethering artifacts but does not mention possible interactions between the tethering procedure and the treatments being tested. Yet Heck \& Wilson (1987) explicitly consider second-order artifacts. In their study, the goal was to assess whether, and to what extent, seagrass in 3 different geographical areas provided protection for several crab taxa. Tethering results were most often found to show significantly lower rates of predation in vegetation than on nearby unvegetated substrates. In a section titled 'Tethering technique and prey species used', Heck \& Wilson (1987) discuss how habitat $\times$ tethering interactions might have affected their conclusions. For example, with respect to portunid crabs, Heck \& Wilson (1987, p. 90) write, 'If tethering significantly affected portunid predator avoidance, as it might by restricting their ability to escape from preda- 
tors, one would expect higher rates of predation on portunids than on other brachyuran crabs which use crypsis as a primary defense. Moreover, anomalously high predation rates on portunids would only have the effect of making it more difficult to reject the null hypothesis of no difference between predation rates in vegetated vs unvegetated substrates or among latitudes, thereby making our analysis more conservative'.

The message in this quotation applies to other tethering studies that evaluate the protective properties of vegetation ( 9 of 22 in Peterson \& Black's (1994) Table 1]. The message is that artifacts produced by vegetation (e.g. by causing tethered individuals to become tangled in vegetation and less able to avoid predators) would only have the effect of making the conclusions more conservative, resulting in failure to reject the null hypothesis of no habitat differences when such differences may in fact have existed (i.e. increasing the probability of Type II error). Studies have consistently found lower mortality of tethered prey in seagrass, despite the possibility of tangling (Heck \& Thoman 1981, Heck \& Wilson 1987, Wilson et al. 1987, 1990). This suggests that potential interactions between treatments and habitats have not led to incorrect conclusions in these studies. Heck \& Wilson (1987) and other authors are aware of potential treatment $x$ tethering artifacts. Peterson and Black (1994) simply fail to recognize this in their review.

Peterson \& Black (1994) inaccurately report another paper by Aronson (1989), which compares predation on tethered ophiuroids between 2 habitats off the British Isles. Again, Peterson \& Black (1994) list the paper as not discussing simple tethering artifacts and not mentioning possible interactions between tethering and treatments (the treatments were different habitats in this study). Once again, the criticized paper does discuss possible artifacts of both types.

Two types of simple tethering artifacts are considered by Aronson (1989) and found to be inconsequential: release of body fluids (again with references) and unnatural behavior of the tethered prey. With regard to those simple tethering artifacts, Peterson \& Black (1994) state, 'Those papers that did acknowledge this simple artifact of tethering tended to respond to this possibility by referring to results as predation potential or relative rates of predation, predation risk, or predator-prey encounters'. Aronson $(1987,1989)$ coined the term 'predation potential' not as some weak excuse for the tethering method but to distinguish it from predation pressure, which is defined as the natural frequency of predatory attacks [a distinction that Peterson \& Black (1994) ignore]. If referring to predation potential is one way in which authors 'acknowledge' simple tethering artifacts (Peterson \& Black 1994), and if Aronson (1989) discusses the fact that tethering exper- iments were employed to measure predation potential (Peterson \& Black 1994), then to conclude in Table 1 that Aronson (1989) does not discuss simple tethering artifacts (also Peterson \& Black 1994) is incorrect.

A good example. In commenting on how authors deal with second-order artifacts, Peterson \& Black (1994) take Aronson particularly to task. They cite Aronson's work as a bad example:

'II]n response to a concern over whether tethering of prey produces artifacts in contrasts of predation among sites because of the novel stimulus of a tethered prey, [Aronson] responds that "the experiment is controlled in the sense that the same stimulus is presented at each site".'

Although this quotation refers specifically to Aronson (1987), a similar statement appears in Aronson (1989). In fact, the latter paper provides a good example of how tethering techniques can be combined with other information not only to consider and test simple and second-order artifacts, but to test ecological hypotheses of a general nature.

In Aronson's (1989) study, tethering experiments were employed to compare the potential for predation on ophiuroids in 2 nearshore habitats. Prior to the experiments, direct observation and perusal of the literature established the identities of the natural predators of ophiuroids at the field sites. Based on theoretical considerations that provided the rationale for conducting the study, the predators were placed in 2 classes. Fish and crabs formed one class and seastars formed the other. Further direct observation established the relative abundances of these 2 classes of predators in the 2 habitats: fish and crabs were abundant in one habitat and rare in the other, whereas seastars were equally abundant in both habitats.

As to the tethering technique, laboratory and field observations confirmed that tethered ophiuroids did not writhe about on their tethers and that they were unable to escape. Laboratory and field observations showed that fish and crabs consumed tethered ophiuroids rapidly, whereas seastars required $>8 \mathrm{~h}$, longer than the duration of each tethering trial. This difference made it possible to distinguish attacks by members of the 2 classes of predators because seastars attacking tethered ophiuroids were necessarily still on top of the ophiuroids at the end of the trial.

In the field trials, nearly 4 times as many tethered ophiuroids were attacked in the habitat in which fish and crabs were abundant. Seastars attacked approximately the same number of tethered ophiuroids in each habitat. The between-habitat difference in attack frequency was therefore due to fish and crabs. Thus, the tethering results, in combination with corresponding differences in patterns of abundance of the 2 classes of predators, support the hypothesis that the 
potential for predation on ophiuroids differed between habitats and that the difference was due to the activity of fish and crabs.

In summary, the same novel stimuli, tethered ophiuroids, were presented in each habitat, as originally claimed (Aronson 1989). One class of predators, seastars, was equally abundant in both habitats and attacked equal, small numbers of tethered prey in both habitats. Fish and crabs, which comprised the other class of predators, were more abundant and attacked more tethered ophiuroids in 1 habitat. Simple and secondorder artifacts were considered and tested, and the conclusions drawn about predation potential were appropriate. It is possible that tethering the ophiuroids increased the success rate of captures by seastars more than it increased the success rate of captures by fish and crabs, as Barbeau \& Scheibling (1994) found for tethered scallops. Such an effect, if it had occurred, would have acted to obscure between-habitat differences.

Conclusions. Despite the problems noted above, Peterson \& Black (1994) highlight an important aspect of benthic ecology: it is an experimental science. Every ecologist knows that all experimental techniques have both good points and bad points. Peterson \& Black's (1994) criticisms of tethering experiments must also be applied to a wide variety of other ecological research techniques. For example, research on herbivory frequently involves presenting herbivores with tethered macrophytes (Hay 1981, 1984, Hay et al. 1983, 1988, Lewis \& Wainwright 1985); these papers were omitted from Peterson \& Black's (1994) review. And as they state themselves, their criticisms also apply to the settling-plate experiments used in larval recruitment studies.

By Peterson \& Black's (1994) reasoning, settling plates made of the same material and placed in different habitats might not be controlled novel stimuli because different larvae in different habitats might respond differently to the artificial primary substratum. Settling-plate experiments are indeed methodologically analogous to tethering experiments. Such experiments measure the potential for recruitment to primary substratum, which is often not available naturally. Both tethering and settling-plate experiments have been and will continue to be enormously useful in marine ecology, but the results must be interpreted cautiously. Menge et al. (1994) provide a recent example of the careful use of experimental measures of both predation potential and recruitment potential.

In conclusion, tethering is the simplest, least timeconsuming method for measuring predation potential. As with all experimental manipulations, tethering has some disadvantages, including potential artifacts that may vary among treatments. We believe that Peterson \& Black (1994) have significantly underestimated the experimental rigor, attention to potential artifacts, and robustness of conclusions in the existing body of tethering studies. Tethering experiments will continue to give ecologists perspective on the process of predation so that they can get on with the business of learning about marine communities.

Acknowledgements. We thank Mark Bertness, Loren Coen, Rom Lipcius, Diana Lipscomb, Bob Steneck, John Valentine and Jon Witman for advice and discussion on the manuscript. This is Contribution No. 270 of the Marine Environmental Sciences Consortium. Partial funding was provided by grants from the National Science Foundation to both authors.

\section{LITERATURE CITED}

Aronson RB (1987) Predation on fossil and Recent ophiuroids. Paleobiology 13:187-192

Aronson RB (1988) Palatability of five Caribbean ophiuroids. Bull mar Sci 43:93-97

Aronson RB (1989) Brittlestar beds: low-predation anachronisms in the British Isles. Ecology 70:856-865

Barbeau MA, Scheibling RE (1994) Procedural effects of prey tethering experiments: predation of juvenile scallops by crabs and seastars. Mar Ecol Prog Ser 111:305-310

Hay ME (1981) Spatial patterns of grazing intensity on a Caribbean barrier reef: herbivory and algal distribution. Aquat Bot 11:97-109

Hay ME (1984) Patterns of fish and urchin grazing on Caribbean coral reefs: are previous results typical? Ecology 65:446-454

Hay ME, Colburn T, Downing D (1983) Spatial and temporal patterns in herbivory on a Caribbean fringing reef: the effects on plant distribution. Oecologia 58:299-308

Hay ME, Duffy JE, Fenical W, Gustafson K (1988) Chemical defense in the seaweed Dictyopteris deliculata: differential effects against reef fishes and amphipods. Mar Ecol Prog Ser 48:185-192

Heck KL Jr, Thoman TA (1981) Experiments on predator-prey interactions in vegetated aquatic habitats. J exp mar Biol Ecol 53:125-134

Heck KL Jr, Wilson KA (1987) Predation rates on decapod crustaceans in latitudinally separated seagrass communities: a study of spatial and temporal variation using tethering techniques. J exp mar Biol Ecol 107:87-100

Lewis SM, Wainwright PC (1985) Herbivore abundance and grazing intensity on a Caribbean coral reef. J exp mar Biol Ecol 87:215-228

Menge BA, Berlow EL, Blanchette CA, Navarette SA, Yamada SB (1994) The keystone species concept: variation in interaction strength in a rocky intertidal habitat. Ecol Monogr 64:249-286

Peterson CH, Black R (1994) An experimentalist's challenge: when artifacts of intervention interact with treatments. Mar Ecol Prog Ser 111:289-297

Wilson KA, Able KW, Heck KL Jr (1990) Predation rates on juvenile blue crabs in estuarine nursery habitats: evidence for the importance of macroalgae (Ulva lactuca). Mar Ecol Prog Ser 58:243-251

Wilson KA, Heck KL Jr, Able KW (1987) Juvenile blue crab, Callinectes sapidus, survival: an evaluation of eelgrass, Zostera marina, as refuge. Fish Bull US 85:53-58

Witman JD (1985) Refuges, biological disturbance, and rocky subtidal community structure in New England. Ecol Monogr 55:421-445 